\title{
Leucas Aspera to Treat Pan Oral Disorders - An Experimental Study
}

\section{S. KARTHIKA NAGARAJAN ${ }^{1 *}$, VIDYA RANI ${ }^{2}$, ARAVINDHABABU NARAYANASAMY ${ }^{3}$ and MAHABOOB KADAR MASTHAN ${ }^{4}$}
Center for Oral Cancer Prevention and Research, Department of Oral Pathology \& Microbiology, Sree Balaji Dental College and Hospitals, Bharath Institute of Higher Education \& Research, Chennai, Tamil Nadu, India.

\begin{abstract}
Objectives: This article aimed at discussing the effectiveness of developing a new antioxidant and anti-inflammatory product from the natural source namely the extract of Leucas aspera plant that can be used to treat various oral mucosal conditions.

Study design: The study was a descriptive experimental study. The dried powder extract of the whole LA plant was subjected to various procedures such as phytochemical analysis, antioxidant assay (DPPH) and assessment of anti-inflammatory effect (Cytokine activity in RAW 264.7 macrophage cells) and the results were tabulated. Significance of anti-inflammatory activity was tested by T-test.

Results: Our analysis has confirmed that $100 \mu \mathrm{g}$ of plant extract showed high amount of antioxidant activity (78\%). The cytokine inhibitory percentage of our plant extract showed consistent increase when tested from $250 \mathrm{ug} / \mathrm{ml}$ to $1000 \mathrm{ug} / \mathrm{ml}$ to be from $24 \%$ to $39 \%$ thus demonstrating significantly high level of anti-inflammatory potential $(P>0.01)$

Conclusion: Our study suggests that LA plant can be safely utilized for testing and developing products based on its extract.
\end{abstract}

\section{Introduction}

The existence of widespread nutritional deficiencies and tobacco related habits makes occurrence of aphthous ulcers and premalignant lesions such as oral leukoplakia, erythroplakia, lichen planus, actinic cheilitis, submucous fibrosis as well as palatal lesions in reverse smokers are more common among the Indian population. The discovery of medicinal plants and their usage in drug manufacturing has attracted many pharmacological companies owing

CONTACT S. Karthika Nagarajan $\$ karthika.shanmuganathan66@ gmail.com 9 Center for Oral Cancer Prevention, Awareness and Research, Department of Oral Pathology \& Microbiology, Sree Balaji Dental College and Hospitals, Bharath Institute of Higher Education \& Research, Chennai, Tamil Nadu, India.

\section{(c) (i)}

(C) 2019 The Author(s). Published by Enviro Research Publishers.

This is an $\partial$ Open Access article licensed under a Creative Commons license: Attribution 4.0 International (CC-BY).

Doi: https://doi.org/10.12944/EDJ.01.01.05 
to their potent pharmacological activities, lower toxicities and economic viability. ${ }^{1}$ The roots and stems of leucas aspera (LA) has demonstrated high antioxidant activity ${ }^{2}$ in comparison to vitamin $E$ and thus can be included as an active formula in treating such potentially malignant disorders. The anti-inflammatory property of leucas aspera would also be beneficial in treatment of aphthous ulcers and stomatitis. Based on the outcome of phytochemical properties, animal studies ${ }^{3}$ and culture analysis; plant extract showed high amount of antioxidant activity. Leucas is an ideal extract to treat the most common oral disorders as a whole; based on its antioxidant and anti-inflammatory efficiency. It can be considered as a potential substrate to develop all-purpose medication for oral topical usage.

The presence of highly potent pharmacological activities, lower toxicities and economic viabilities have sorted many pharmacological companies to utilize medicinal plant for preparing drugs. ${ }^{1}$ These indigenous medicinal plants have opened a new arena

\section{Table 1: Phytochemical Analysis} of herbal extract

\begin{tabular}{ll}
\hline $\begin{array}{l}\text { Chemical test } \\
\text { - Extract }\end{array}$ & $\begin{array}{l}\text { Presence/ } \\
\text { Absence }\end{array}$ \\
\hline Carbohydrate & \\
Fehling's test & +++ \\
Molisch test & ++++ \\
Alkaloids & \\
Dragendroff's test & ++ \\
Wagner's test & ++ \\
Hagers's test & +++ \\
Mayer's test & ++++ \\
Glycosides & \\
Keller Killani test & ++++ \\
Saponins & \\
Foam test & ++++ \\
Phenolic compounds & \\
and tannin & \\
Ferric chloride test & \\
Test for Sterols & ++++ \\
(++) = Moderate content & \\
$(+++)=$ Nubstantial content & \\
$(++++)=$ high content & \\
$(-)=$ Absent. & \\
\hline
\end{tabular}

for drug development. The presence of antioxidant properties in addition to antimicrobial properties has kindled new interests in the development of these plant-based products on premalignant lesions and conditions of the oral cavity.

Various commonly occurring oral lesions do not have a simple topical pharmacological management and require per-oral medications or invasive procedures such as biopsies for their effective treatment. Major lesions of importance are as follows:

Oral Squamous Cell Carcinomas (OSCC) are principally induced by free radicals such as reactive oxygen and nitrogen species (ROS and RNS) through oxidative and nitrative stress. ${ }^{4}$ The free radicals as well as protein damage play key roles in carcinogenesis as they cause DNA base alterations, strand breaks, damaged tumor suppressor genes, and proto-oncogenes expression. RNS occurs in the form of ROS such as superoxide radicals $\left(\mathrm{O}_{2}\right)$, hydroxyl radicals $(\mathrm{OH})$, nitrosamines $\left(\mathrm{NO}_{3}\right.$ and $\left.\mathrm{NO}_{2}\right)$; and hydrogen peroxide $\left(\mathrm{H}_{2} \mathrm{O}_{2}\right) .4$

\section{Recurrent Aphthous Stomatitis (RAS)}

Recurrent, multiple, small, round, or ovoid ulcers with circumscribed margins, having yellow or gray floors. This is a relatively more common painful condition among various populations. The ulcers first appear during childhood or adolescence and are marked by erythematous haloes surrounding them. ${ }^{5}$

Oral Submucous Fibrosis (OSMF) is one of oral potentially malignant disorders owing to the habit of chewing areca nut. It is a chronic condition of insidious origin and can affect all parts of oral cavity including pharynx. It can also be associated with vesicle formation that may precede the lesion proper sometimes. Histology the condition can be defined as having a juxta-epithelial inflammatory reaction followed by a fibroelastic change of the lamina propria, with epithelial atrophy leading to stiffness of the oral mucosa. It causes trismus and inability to eat as a clinical manifestation. ${ }^{6}$

Oral Leukoplakia (OL) has been defined by World Health Organization (1978) "as a white patch or plaque which cannot otherwise be characterized clinically or pathologically as any other disease". 
The other potentially malignant disorders are palatal lesions in reverse smokers, erythroplakia, actinic cheilitis and lichen planus. ${ }^{7}$ Erythroplakia and leukoplakia are far more common lesions in tobacco users. The malignant transformation potential of leukoplakia is $0.13 \%$ to $17.5 \%$ and OSMF is $2-8 \% 7,8$. The current protocol in the management of potential malignant disorders is habit intervention followed by active treatment in case of erythroplakia as well as leukoplakia. The non-surgical management of leukoplakia includes treating the lesions using carotenoids, vitamins, bleomycin and photodynamic therapy. The more accessible and circumscribed lesions were treated with excisional biopsy.

\section{Materials and Methods Preparation of Plant Extract}

The leaves, stem, roots and flowers of the plant were sundried for 1 week and were ground into fine powder using regular food processor. The obtained powder was soaked in $500 \mathrm{ml}$ methanol $(80 \% \mathrm{v} / \mathrm{v})$ and kept at room temperature (28-30 degree centigrade) for 4 days. The Whatman's filter paper was used to filter the extract and the obtained fluid was utilized for various analysis.

\section{Phytochemical Analysis}

The obtained extract was run through various phytochemical analysis and the results were tabulated. $10 \mathrm{mg}$ of plant extract is dissolved in $10 \mathrm{ml}$ of methanol $(1 \mathrm{mg} / \mathrm{ml})$ and $500 u l$ extract was used for each reaction. Tests for carbohydrates, flavonoids, sterols, alkaloids, glycosides, saponin, phenolic compounds and sterols were done.

\section{Antioxidant Assay}

The extract was also analyzed for the presence of antioxidant activity which showed significant scavenging action.

\section{Anti-Oxidant Activity}

2, 2-diphenyl-1-picrylhydrazyl (DPPH) assay:

The colorimetric DPPH assay by Shimada et al., (1992) ${ }^{8}$ was utilized to determine the radical scavenging activity of the plant extracts.

\section{Principle of the Assay}

The assay is based on the hydrogen donating capacity of test samples. This capacity is quantified in terms of their ability to scavenge the relatively stable, organic free radical DPPH and by their consequent reduction. The DPPH solution colored deep violet was measured at 550nm. In the event of subsequent reduction; decolorization to yellow-white occurs. The degree of reduction can be measured stoichiometrically. The radical scavenging activity of sample extract will correspond inversely to DPPH measured earlier at $550 \mathrm{~nm}^{8}$

\section{Spectrophotometric Determination of the Antioxidant Activity of the Plant Extract}

The radical scavenging activity of the extract at different concentrations prepared using ethanol was obtained after utilizing a 96-well microtiter plate to generate the quantitative measure. The methanol extract with different concentrations were prepared. DPPH solution was prepared in ethanol. Aliquots of plant extract prepared in ethanol is added to DPPH solution. This plate was shaken

Table 2: DPPH assay - Absorbance of the extracts at $595 \mathrm{~nm}$

\begin{tabular}{llll}
\hline $\begin{array}{l}\text { Volume taken from } \\
\text { extract (ul) }\end{array}$ & $\begin{array}{l}\text { Amount of extract- } \\
\text { Content(ug) }\end{array}$ & $\begin{array}{l}\text { Absorbance } \\
\text { (OD) at 595nm }\end{array}$ & $\begin{array}{l}\text { \% scavenging } \\
\text { activity }\end{array}$ \\
\hline Blank(methanol) & & 0.9988 & \\
0.1ul & $0.1 \mathrm{ug}$ & 0.7861 & 21.17 \\
$0.5 \mathrm{ul}$ & 0.5ug & 0.4462 & 55.2 \\
1ul & 1ug & 0.3620 & 63.63 \\
10ul & 10ug & 0.2944 & 70.40 \\
30ul & 30ug & 0.2536 & 74.48 \\
100ul & 100ug & 0.2115 & 78.70 \\
\hline
\end{tabular}


mildly for $2 \mathrm{~min}$, after which it was stored in the dark for $30 \mathrm{~min}$. The microplate reader was used to measure the decolorization spectroscopically at $595 \mathrm{~nm}$. The negative controls contained plant extract to methanol was added, in the absence of DPPH. Percentage purple decolorization to DPPH yellow was then determined for samples as a measure of the free radical scavenging activity. Lower absorbance of the reaction mixture indicated higher free radical scavenging activity. $\%$ DPPH radical-scavenging = (Absorbance of control-Absorbance of test Sample) X100 (Absorbance Of control) ${ }^{8}$

\section{Anti-Inflammatory Properties of LA}

In addition to various other functions of $\mathrm{IL}-1 \beta$; it also is an inflammatory mediator and is involved in a variety of cellular activities, including cell proliferation, differentiation, and apoptosis. IL-1 $\beta$ which will be produced by activated macrophages is proteolytically processed to its active form by caspase 1 (CASP1/ICE). The Central Nervous System (CNS) activation through cyclooxygenase-2 (PTGS2/COX2) by this cytokine is found to contribute to inflammatory pain hypersensitivity. ${ }^{9}$ The LA extract was tested for the effective inhibition of the IL-1 $\beta$ obtained from RAW 264.7 macrophages. ${ }^{8}$

\section{Cell Culture}

Mouse macrophage cell line RAW 264.7 obtained from National Center for Cell Science (Pune, India) was utilized for the purpose. The RAW 264.7 macrophages were cultured in DMEM medium. Dulbecco's Modified Eagle's Medium (DMEM)) containing 10\% fetal bovine serum (FBS) supplemented with antibiotics solution was used to culture the cells. The cells were grown at $37^{\circ} \mathrm{C}$ and $5 \% \mathrm{CO}_{2}-95 \%$ air under humidified conditions. A 96-well microplate was used for culturing RAW 264.7 macrophages at an initial density of $1 \times 10^{4}$ cells/well for $24 \mathrm{~h}$. The cells were subsequently treated with plant extract at various concentrations (250, 500, or $1000 \mu \mathrm{g} / \mathrm{mL})$ and LPS $(1 \mu \mathrm{g} / \mathrm{mL})$ for additional 24 hours. LPS was dissolved in DMEM. The cells were stimulated with plant extract and LPS $(1 \mu \mathrm{g} / \mathrm{mL})$ for $24 \mathrm{~h}$ to assess the effect of plant extract on the production of IL-1 in the LPS-induced RAW 264.7 macrophages and the cell culture supernatants were collected. An ELISA kit was used to measure the IL-1 $\beta$ content of the supernatants according to the manufacturer's protocol and absorbances (nm) were also recorded using a microplate reader. ${ }^{8}$

\section{Preparation of Samples for ELISA}

The kit used was Human osteocalcin ELISA Kit, Catalogue No.: EH3468 from Fn-Test China;Range: $1.25-80 \mathrm{ng} / \mathrm{ml}$, Sensitivity: $<0.75 \mathrm{ng} / \mathrm{ml}$. The sample preparation was done by cell lysate. Trypsin was utilized to detach adherent cells. 1)cell suspensions were collected by direct centrifugation. 2) cells were washed thrice in PBS. 3) cells were re-suspended in PBS and subjected to lysis using RIPA buffer and frozen cells at $-20^{\circ} \mathrm{C}$. 4) cells were thawed. 5) Centrifuged at $1000 \times \mathrm{xg}$ (or $3000 \mathrm{rpm}$ ) for 15 minutes at $2-8^{\circ} \mathrm{C}$ to remove cellular debris. 6) Samples stored at $-20^{\circ} \mathrm{C} .^{8}$

Cytokine Activity of the LA in RAW 264.7 Macrophage Cells

Enzyme-linked immunosorbant assay (ELISA) technique was carried out using simultaneous profiling of the level of multiple cytokines and/or

Table 3: Cytokine inhibitory effect of the LA extract

\begin{tabular}{llllll}
\hline & \multicolumn{5}{c}{ pg/ml (IL-1Beta levels) } \\
\cline { 2 - 5 } Details & $\mathbf{1}$ & $\mathbf{2}$ & $\mathbf{3}$ & $\begin{array}{l}\text { Cytokine } \\
\text { levels(pg/ml) }\end{array}$ \\
\hline $\mathrm{ug} / \mathrm{ml}$ & 1000 & 1000 & 1000 & 1000 & \% Inhibition \\
250 & 726.8312 & 651.8812 & 788.961 & 717.3733 & 23.85291 \\
500 & 706.1918 & 672.0792 & 707.5758 & 689.0383 & 26.86059 \\
1000 & 602.9947 & 561.5842 & 589.1775 & 574.7673 & 38.99012 \\
LPS(1ug/ml) & 937.2724 & 968.3168 & 913.4199 & 942.0889 & \\
media & 109.2675 & 122.7723 & 92.64069 & 108.3764 & \\
\hline
\end{tabular}


chemokines. This was carried out in conventional and simple sandwich-based ELISA. The target-specific capture antibodies were used to coat the 96-well ELISA microplate; one in each eight-well strip. Profiling results from up to six samples was obtained. Reagent included the corresponding detection antibodies, Antigen Standards, and a complete set of detection reagents for a colorimetric ELISA. ${ }^{8}$

\section{Assay Protocol}

The capture antibodies were incubated to bind their specific protein of interest. The unbound protein was washed away. The captured analyte in the wells was treated with biotinylated detection antibodies. The wells were washed to remove unbound material. An avidin-horseradish peroxidase conjugate was added. The wells were again washed and a colorimetric substrate solution was added, which produced a blue color in direct proportion to the amount of protein analyte present in the initial sample. The stop solution was added to stop color development. The absorbance at $450 \mathrm{~nm}$ was read and compared across samples. All wells of an eight-well strip were coated with the same capture antibody for the same cytokine or chemokine. ${ }^{8}$

The procedure followed include all reagents to be prepared. The samples, positive and negative controls were set up. A $50 \mu$ lassay buffer was added into each well of ELISA Array plate. Compound treatment done using $1000 \mathrm{ug} / \mathrm{ml}, 500 \mathrm{ug} / \mathrm{ml}$ and $250 \mathrm{ug} / \mathrm{ml}$ of plant extract. The samples and control samples $50 \mu \mathrm{l}$ each were transferred into the appropriate wells of the ELISA Array plate and incubated for 2 hours. After three washes; 100 $\mu l$ of Detection Antibody solution was added and incubated for 1 hour. After three washes $100 \mu \mathrm{l}$ Avidin-HRP added and incubated for 30 minutes. The $100 \mu$ l development solution was added after 4 washes and incubated for 15 minutes in the dark.
Finally; $100 \mu$ l of stop solution was added and read at OD450nm within 30 minutes. A standard curve was plotted relating the intensity of the color (O.D.) to the concentration of standards. The OD concentration in each sample was interpolated from the standard curve obtained. ${ }^{8}$

\section{Results}

The plant extract subjected to various procedures such as phytochemical analysis, Antioxidant assay (DPPH) and Anti-Inflammatory properties assay (Cytokine activity in RAW 264.7 macrophage cells) have been reported as follows:

\section{Phytochemical Analysis}

The 500ul plant extract was subjected to tests for carbohydrates, flavonoids, sterols, alkaloids, glycosides, saponin, phenolic compounds and sterols. The results are tabulated in Table 1. The given plant extract from LA showed high amounts of carbohydrates, glycosides and saponins. Significant amounts of alkaloids and Phenolic compounds. There were no sterols isolated from the extract.

\section{Antioxidant Capacity using DPPH Assay}

The free radical scavenging activity of LA extract revealed the concentration with maximum antioxidant capacity as tabulated in Table 2 . The percentage of scavenging capacity was obtained through the following formula and the reading was done at OD $595 \mathrm{~nm}$

$\%$ DPPH radical-scavenging = (Absorbance of control -Absorbance of test Sample/ (Absorbance Of control)) X100

The percentage of scavenging activity crossed 50 when the concentration of $0.5 \mathrm{ml}$ of extract was added and continued to increase to $63.63,70.40,74.48$ percent at $1 \mathrm{ul}, 10 \mathrm{ul}, 30 \mathrm{ul}$ and reached $78 \%$ at $100 \mathrm{ml}$

Table 4: Anti-inflammatory activity of LA extract at various concentrations and its significant cytokine inhibitory effect

\begin{tabular}{llllll}
\hline $\begin{array}{l}\text { Plant extract } \\
\text { concentration }\end{array}$ & $\begin{array}{l}\text { Absorbance } \\
\text { Mean }\end{array}$ & $\begin{array}{l}\text { Mean Cytokine } \\
\text { Level }\end{array}$ & SD & t value & P value \\
\hline ug_250 & 0.333 & 717.37 & 317.22 & 5.254 & .003 \\
ug_500 & 0.347 & 689.04 & 319.10 & 5.088 & .004 \\
ug_1000 & 0.484 & 574.77 & 323.34 & 5.166 & .004 \\
\hline
\end{tabular}


concentration. The combined extract of the LA plant thus has highly significant antioxidant capacity as indicated in Figure 1.

Cytokine activity in RAW 264.7 macrophage cells: Compound treatment done using $1000 \mathrm{ug} / \mathrm{ml}$, 500ug/ $\mathrm{ml}$ and $250 \mathrm{ug} / \mathrm{ml}$ of plant extract on Multi-Analyte ELISA Array Kit for Cytokine activity of the LA in RAW 264.7 macrophage cells on 96 well ELISA microplate showed the results as per Table 3 . The interleukin (IL-1ß) level and its inhibition was assessed as an indicator of anti-inflammatory activity of the LA extract (Figure 2). The results were analyzed using $t$ test for statistical significance.

\section{Discussion}

The phytochemical analysis of LA reveals that its high content of carbohydrates, alkaloids, saponins, Phenols and tannins indicating high potential form medicinal value.
The antioxidant and scavenging ability of phenolic compounds against free radicals is a well-established factor. ${ }^{10,11} \mathrm{~A}$ study proves that phenolics expressed major antioxidant activity of the selected edible flowers. ${ }^{10}$ Do et al., revealed that naturally occurring polyphenolics showed the highest antioxidant capacity when compared to synthetic alternatives. ${ }^{12}$ The high content of Phenols and Tannins in the LA plant extract (Table 1) reveals that it has sufficient amounts of antioxidant activity being a natural source.

DPPH assay can be used to measure the free radical scavenging action of a compound..$^{13} \mathrm{DPPH}$ is a stable free radical that can accept an electron or hydrogen radical to become a stable diamagnetic molecule. DPPH is of deep purple colour with absorption maximum at $517 \mathrm{~nm} .{ }^{14}$ Antioxidants present in an extract changes DPPH to a colourless compound (2,2-dipenyl-1-picryl hydrazine) due to quenching of

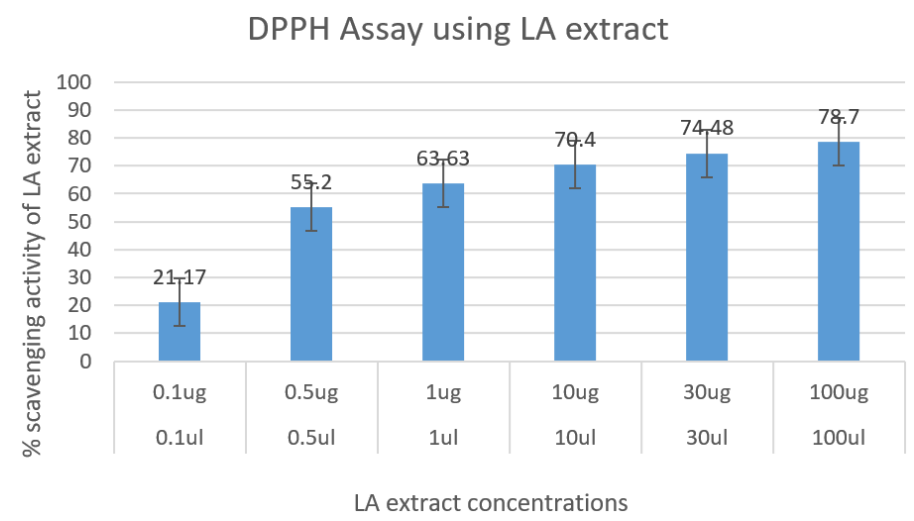

Fig. 1: DPPH assay measuring the antioxidant capacity of the LA extract

\section{IL-1Beta levels at various concentrations of} plant extract

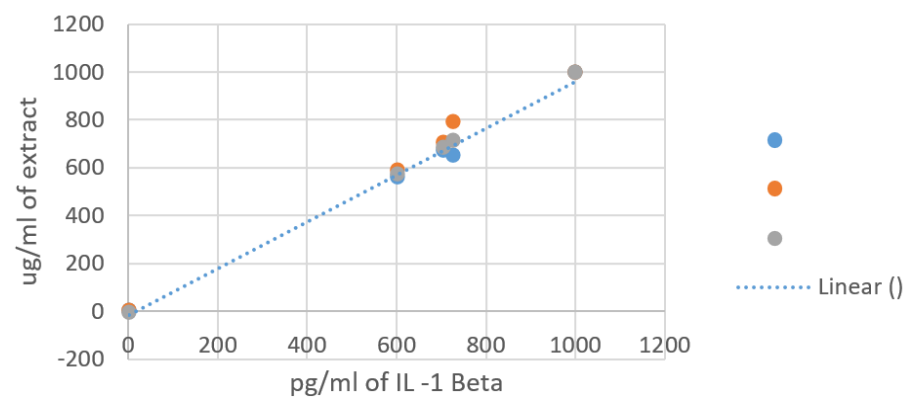

Fig. 2: IL-1 Beta levels plotted against of various concentrations of LA extract 
DPPH free radicals and hence used as a substance to evaluate the antioxidant activity. ${ }^{15,16}$ In our study, the plant extracts had significant scavenging effects on the DPPH radical which increased with the increase in the concentration of the sample. The 100ug extract demonstrated $78 \%$ antioxidant activity when 0.5 ug itself demonstrated $55 \%$ antioxidant activity proving the extract will be a significantly powerful anti-oxidant (Table 2, Figure 1). Further, the antioxidant activity increased consistently on increasing the concentration of plant extract from $1 \mathrm{ul}, 10 \mathrm{ul}, 30 \mathrm{ul}$ and $100 \mathrm{ul}$ to show $63.63,70.40,74.48$ and $78.70 \%$ scavenging ability thus proving the effectiveness of the plant extract (Figure 1). While the synthetic analogue would cost more; the relatively inexpensive LA plant extract will be able to provide a readily available free radicle scavenge without any adverse effects. High content of tannins also provide credence to local usage of such compound in oxidative stress induced ailments. ${ }^{11}$

Anti-inflammatory effects in LPS stimulated RAW264.7 cells were studied using ELISA. Any Infection or irritation results in inflammation as the first response. Inflammation is the result of cytokine activity such as TNF- $\alpha$, IL-1, IL-6, and by eicosanoid such as PGE2. ${ }^{17}$ LPS is well known to activate two following downstream pathways: the MyD88 and TRIF-dependent pathways. ${ }^{18}$ The activation of caspase- 1 enabled by LPS and ATP stimulation induced robust release of IL-1 $\beta$. IL-1 $1 \beta$ is an important pro-inflammatory cytokine in cancer formation. In addition to many immune reactions; mature IL-1 $\beta$ is involved in the recruitment of inflammatory cells to the site of infection19. Monocytes, macrophages and accessory cells secrete IL-1 $\beta$ as a soluble protein. These are involved in the activation of T-lymphocytes and B-lymphocytes. Lymphocyte response to antigens or mitogens is mediated by $\mathrm{IL}-1 \beta$ and is released early in an immune response20. Interleukin-1 beta can be activated by a second signaling mechanism involving the inflammasome and caspase 1 . The rate-limiting step in the release of IL-1 $\beta$ is the translation of mRNA into the $\mathrm{IL}-1 \beta$ precursor. ${ }^{10}$ Active form of monocytes and caspase- 1 are already present in circulation. When the monocyte is stimulated to synthesize the IL-1 $\beta$ precursor; cleavage of the precursor takes place and mature IL-1 $\beta$ is secreted over several hours 21 . $\mathrm{IL}-1 \beta$, also called endogenous pyrogen, has ability to high level regulation both transcriptionally and post-transcriptionally. It can be induced transcriptionally through number of pathways including through Toll-like receptors (TLRs), which may be activated by microbial pathogens, or by cytokines including TNF- $\alpha$ (tumor necrosis factor- $\alpha$ ) and as well as IL-1 $\beta$ itself. These pathways lead to activation of transcription factors, particularly $\mathrm{NF}-\kappa \mathrm{B} .{ }^{21}$

The Cytokine inhibitory percentage of our plant extract showed consistent increase when tested from $250 \mathrm{ug} / \mathrm{ml}$ to $1000 \mathrm{ug} / \mathrm{ml}$ to be from $24 \%$ to $39 \%$ (Table 3,4, Figure 2) thus demonstrating significantly high level of anti-inflammatory potential $(P>0.01)$.

\section{Conclusion}

Based on these findings there is concrete evidence that Leucas aspera might be considered as a wonder drug to treat many stress induced oral conditions which are on the rise in the modern world. This requires further investigative studies before being able to be clinically used.

\section{Acknowledgement}

I would like to acknowledge the effortless guidance and help rendered by Dr. Savithri Sivakumar for carrying out the biochemical analysis related to our study.

\section{Funding}

COCPAR, Bharath Institute of Higher education and Research seeding grant

\section{Conflict of Interest}

Nil

\section{References}

1. Prashant KR, Dolly J, Singh KR, Gupta KR, Watal G. 2008. Glycemic properties ofTrichosanthes dioica leaves. Pharm Biol. 46(12): 894-899.
2. Chew AL, Jessica JJA, Sasidharan S. 2012. Antioxidant and antibacterial activity of different parts of Leucas aspera. Asian Pac J Trop Biomed. 2(3): 176-180 
3. Kripa KG, Chamundeeswari D, Thanka J. 2011. Acute and Sub-Acute Toxicity Evaluation Of Ethanolic Extract Of Leucas aspera (Lamiaceae) In Experimental Rats. Int. J. Drug Dev. \& Res. 3 (3): 339-347

4. Patel RP, McAndrew J, Sellak $\mathrm{H}$, et al., 1999. Biological aspects of reactive nitrogen species. Biochem Biophys Acta.1411: 385-400.

5. L Preeti, KT Magesh, K Rajkumar, Karthik R. 2011.Recurrent aphthous stomatitis. J Oral Maxillofac Pathol. 15(3): 252-256.

6. Pindborg JJ, Sirsat SM. 1966. Oral Submucous fibrosis. Oral Surg Oral Med Oral Pathol. 22: 764-79.

7. Warnakulasuriya S, Johnson NW, van der Waal I. 2007. Nomenclature and classification of potentially malignant disorders of the oral mucosa. J Oral Pathol Med. 36:575-80.

8. Ray JG, Ranganathan K, Chattopadhyay A. 2016. Malignant transformation of oral submucous fibrosis: Overview of histopathological aspects. Oral Surgery, Oral Medicine, Oral Pathology and Oral Radiology. 122(2):200-209.

9. Shimada K., Fujikawa K., Yahara K., Nakamura T. 1992. Antioxidative properties of xanthone on the auto oxidation of soybean in cylcodextrin emulsion. J. Agr. Food Chem. 40:945-948.

10. Bensi G, Raugei G, Palla E, Carinci V, Tornese Buonamassa D, Melli M. 1987. "Human interleukin-1 beta gene". Gene. 52 (1): 95-101.

11. Xiong L, Yang J, Jiang $\mathrm{Y}$, Lu B, Hu Y, Zhou F, Mao S, Shen C. 2014. Phenolic compounds and antioxidant capacities of 10 common edible flowers from China. J Food Sci.79(4):C517-25.

12. Mbaebie B, Edeoga H, Afolayan A. 2012. Phytochemical analysis and antioxidants activities of aqueous stem bark extract of Schotia latifolia Jacq. Asian Pacific Journal of Tropical Biomedicine. 2(2):118-124.

13. Kim DO, Lee CY. 2004. Comprehensive study on vitamin $C$ equivalent antioxidant capacity (VCEAC) of various polyphenolics in scavenging a free radical and its structural relationship. Crit Rev Food Sci Nutr. 44(4):25373.

14. Senguttuvan J, Paulsamy S, Karthika K. 2014. Phytochemical analysis and evaluation of leaf and root parts of the medicinal herb, Hypochaeris radicata L. for in vitro antioxidant activities. Asian Pacific Journal of Tropical Biomedicine. 4(Suppl 1): S359-S367.

15. Sumathy R, Sankaranarayanan S, Bama $\mathrm{P}$, Ramachandran J, Vijayalakshmi M, Deecaraman M.2013. Antioxidant and antihemolytic activity of flavonoids extract from fruit peel of Punica granatum. Asian $J$ Pharm Clin Res. 6(2):211-214.

16. Shah $R$, Kathad $H$, Sheth $R$, Sheth $N$. 2010. In vitro antioxidant activity of roots of Tephrosia purpurea Linn. Int J Pharm Pharm Sci.2(3):30-33.

17. Bijaya LM, Bikash B. 2013. Antioxidant capacity and phenolics content of some Nepalese medicinal plants. Am J Plant Sci. 4:1660-1665.

18. Chun S-C, Jee SY, Lee SG, Park SJ, Lee JR, Kim SC. 2007. Anti-Inflammatory Activity of the Methanol Extract of Moutan Cortex in LPS-Activated Raw264.7 Cells. Evidencebased Complementary and Alternative Medicine : eCAM.4(3):327-333.

19. Xie Q, Shen WW, Zhong J, Huang C, Zhang L, Li J. 2014. Lipopolysaccharide/adenosine triphosphate induces IL-1 $\beta$ and IL-18 secretion through the NLRP3 inflammasome in RAW264.7 murine macrophage cells. Int $J$ Mol Med.34(1):341-9

20. Liu J, Yang T, Liu Y, Zhang H, Wang K, Liu M, Chen G, Xiao X. 2012. Krüppel-like factor 4 inhibits the expression of interleukin-1 beta in lipopolysaccharide-induced RAW264.7 macrophages. FEBS Lett.586(6):834-40.

21. Goto, M., Katayama, K.I., Shirakawa, F. and Tanaka, I. 1999. Involvement of NF-kappaB p50/p65 heterodimer in activation of the human pro-interleukin1beta gene at two subregions of the upstream enhancer element. Cytokine.11,16-28.

22. Dinarello, C.A. 2011. A clinical perspective of $\mathrm{IL}-1 \mathrm{~b}$ as the gatekeeper of Inflammation. Eur. J. Immunol. 41:1203-1217. 